Proceedings

\title{
Dispersion and Binomial Sequential Sampling Plan for Lesser Date Moth Batrachedra amydraula (Lepidoptera: Batrachedridae) Infesting Date Palm Plantations ${ }^{\dagger}$
}

\author{
Aqeel Alyousuf 1,**, Rusul A. Abood ${ }^{2}$ and Mohammed M. Alderawii ${ }^{2}$
}

Citation: Alyousuf, A.; Abood, R.A.; Alderawii, M.M. Dispersion and Binomial Sequential Sampling Plan for Lesser Date Moth Batrachedra amydraula (Lepidoptera: Batrachedridae) Infesting Date Palm Plantations, in Proceedings of the 1st International Electronic Conference on Entomology, 1-15 July 2021, MDPI: Basel, Switzerland, doi:10.3390/IECE-10531

Published: 1 July 2021

Publisher's Note: MDPI stays neutral with regard to jurisdictional claims in published maps and institutional affiliations.

Copyright: (C) 2021 by the authors. Submitted for possible open access publication under the terms and conditions of the Creative Commons Attribution (CC BY) license (http://creativecommons.org/licenses /by/4.0/).

\author{
1 Department of Plant Protection, College of Agriculture, University of Basrah, Basra, Iraq; \\ aqeel.alyousuf@okstate.edu \\ 2 Department of Plant Protection, Iraqi Ministry of Agriculture, Basra, Iraq; \\ * Correspondence: aqeel.alyousuf@okstate.edu \\ † Presented at the 1st International Electronic Conference on Entomology (IECE 2021), 1-15 July 2021; \\ Available online: https://iece.sciforum.net/.
}

\begin{abstract}
The Lesser Date Moth (LDM) Batrachedra amydraula (Lepidoptera: Batrachedridae) is a serious pest of fruits of date palm trees that causes economic losses in nearly all growing regions globally. As one of the main methods for controlling this pest, the overuse of broad-spectrum insecticides is applied. Population sampling methods are fundamental in the chemical control-based IPM system, minimizing the negative effects of insecticides on the environment. A tentative sampling method for LDM is recommended; however, conventional sampling schemes are complained due to the time-consuming. Alternatively, binomial sequential sampling plans are often more efficient and may allow samplers to fast classify pest infestations and make a control decision. The objectives of this study were to determine the spatial distribution and develop binomial sequential sampling for fast reliable estimation of LDM infestation on date palms. Throughout the province of Basra, Iraq, eighty-four 1 ha date palm orchards were sampled from 2017 to 2019. The results of spatial distribution pattern analyses by using TPL $(a=0.0695$ and $b=1.4041)$ indicated that LDM on sampling units (date palm spikelets) were highly aggregated in date palm orchards. The mean vs. proportion infested (PT-m) ( $T=0$ to 5 ) models for LDM infesting sampling units (spikelets) revealed relatively strong fits for LDM. Binomial sequential sampling models for LDM infesting date palms were developed for action thresholds of $0.15,0.25$, and 0.35 proportions of spikelets with at least three infested fruit $(T=3)$. Binomial sequential sampling plans were validated using RVSP software by the evaluation of operating characteristic functions and average sample number. We recommend a minimum sample size of 28 and sampling efforts should be terminated at 90 samples for these sampling plans.
\end{abstract}

Keywords: Batrachedra amydraula; Binomial; date palm; Dispersion; Sequential Sampling

\section{Introduction}

Date palm tree Phoenix dactylifira (Palmales: Palmae) is one of the most important fruit trees in the Arabian Peninsula including Iraq, Saudi Arabia, and UEA, and many other countries of the world [1]. The total production of table date fruits was 1,132 million metric tons globally in 2019/2020 [2]. In Iraq, the production of palm dates amounted to approximately 735,353 tons with a yield average of $66.7 \mathrm{Kg} / \mathrm{palm}$ in 2020 [3]. The Lesser Date Moth (LDM) Batrachedra amydraula (Lepidoptera: Batrachedridae) is a key pest of the fruits of date palms on a wide geographical range, extending from North Africa to the Middle East, as well as Pakistan and India [4-6]. Moths of this pest lay eggs on the fruits, and larvae feed on both the immature and mature fruits, that causes gradually wilting and drying of the fruits. Then, the color of infested fruits turns brown, and the large fruits 
usually fall to the ground ultimately $[7,8]$. The insect infests all varieties of date palm, causing economic losses which may reach $25 \%$ where the palms left without management [9]. In heavy infestation, these losses can be up to $100 \%$, which leads to stripping the bunch from the fruits $[7,10]$.

In Iraq, pheromone traps is considered the most resourceful way to monitor LDM moths and make a decision to determine timely pesticide use [11]. One of the major limitations of monitoring by these traps is that it has not been proven in scientific research, and unfortunately, farmers usually spray without proper assessment of LDM intensity [12]. A reliable estimate of pest abundance is primarily required for integrated pest management. As an ecosystem-based strategy, IPM applied to manage pests or limit their damage through the optimal use of available pest control techniques based on cost/benefit analysis, that minimizing risks to human health and the environment [13].

The development of suitable sampling plans is fundamental to precisely estimate insect abundance or infestation levels based on Economic threshold (ET) to apply better possible control practice for the pests [14]. Sampling plans are usually developed upon the categorization of the dispersal of the pests with specified sampling procedures and sampling units [15]. Spatial distribution of pests is usually affected by the nature of the components of plant hosts, as well as being affected by the competition factor among the same species as (Interspecific competition) and among the different species (Intraspecific Competition) $[16,17]$. The spatial distribution or the aggregation degree of pest greatly affects the sample size requirements of the developed sampling programs, which classify the population densities around the critical economic boundary $[18,19]$. However, various studies of dispersal for the pests infesting date palms were done to build a sampling protocol for estimating the pest densities within their host plant habitat for the carob moth, Ectomyelois ceratoniae (Zeller) (Lepidoptera: Pyralidae) infested the fruits of date palms in California Date Gardens [20,21], Parlatoria blanchardi (Targioni-Tozzetti) (Hemiptera: Diaspididae) on Date Palm trees to develop a fixed size sampling plan in Iran [22], and for Rhynchophorus ferrugineus (Olivier), which was aggregated pattern in date palm plantations of Saudi Arabia [23].

A sampling plan with a fixed sample size is usually unproductive because it is timeconsuming during sampling fields with low or high pest abundance [24]. Alternatively, Sequential sampling programs are very effective for estimating or classifying the pest population density for making an appropriate decision regarding pest control [25-28], that reducing time and efforts spending in collecting samples [15,29].

Several sequential sampling programs have been developed to estimate the densities of numerous pests infesting crops, such as aphids (Hemiptera) [30-35], lepidopteran pests [36-38], and coleopteran pests [39-41], as well as the insects attacking the fruit trees, such as fruit flies and borers [42-44].

The time needed to count pests is maybe the most significant limitation for developing the sampling schemes. Scouting of initial population densities of LDM is difficult due to its ambiguous life stages and a time interval lag between early occurrence and the presence of signs or symptoms of infestation, all of which make it challenging to estimate this pest density [10]. It is concerned that precisely counting of LDM density per tree required considerable times, and the sampler may be unwilling to spend the necessary time, even though the sequential sampling plan is credible (A. Alyousuf, personal observations). Another possibility, binomial (presence/absence) sampling plans, which are built on the expectable relationship between population densities of the pest and the proportions of sampling units infested within the habitats, could offer a more capable method especially if adapted to sequential sampling plans [29]. This type of sampling plan can reduce more time and effort, thus reducing costs by more than $50 \%$ of sampling programs, compared to the numerical sequential sampling programs [45-47]. Binomial sequential sampling has been developed for various pests, such as aphids infesting cereals [48-50]; Listronotus maculicollis (Coleoptera: Curculionidae) larvae cause damage to turfgrass[51] and Macadamia Felted Coccid (Hemiptera: Eriococcidae) infested Macadamia plantations [51]. However, 
currently, no sampling plans are available for estimating LDM density. Our objectives were to determine the spatial distribution and develop a binomial sequential sampling plan for IPM-decision-making for LDM in Date palms.

\section{Material and Methods}

Throughout the province of Basra, Iraq, 84 commercial production date palm plantations were selected for sampling LDM from April to July of 2017, 2018, and 2019. Each selected plantation was at least 1 hectare and consisted of 140 to 160 date palm trees. Randomly, three trees were selected at each plantation, and 16 spikelets (25-35 fruits in each spikelet) from different date palm bunch stalks per a date palm tree were examined for infested fruit by LDM larvae. Usually, the infested fruits that have small holes close to the pedicel showed typical symptoms of LDM attack. The numbers of infested fruits were counted and recorded. Data set of 28 (sampled during 2019) from the 84 plantations were not included for developing binomial sampling plan but were used to validate the sampling plans.

\subsection{Spatial Distribution Analysis}

Spatial distribution pattern of LDM infestation was estimated form all data set, except the data which utilized for validation, using Taylor's power law (TPL) and clumping parameter $K$ values [25]. TPL defines the relationship between mean $(m)$ and variance $\left(s^{2}\right)$ for infested fruits as (equation 1):

$$
s^{2}=a m^{b}
$$

where " $a$ " is referred to as a "sampling factor" and " $b$ " is considered an "index of aggregation" and indicates a uniform/regular $(b<1)$, random $(b=1)$, or aggregated/clumped ( $b$ $>1$ ) distribution. Regressions were performed after a natural logarithm (ln) transformation for estimating the parameters $a$ and $b$ [52] (equation 2):

$$
\ln \left(s^{2}\right)=\ln (a)+b \ln (m)
$$

where the parameters, $\ln (a)$ and $b$ are the intercepts and the slope of the regression model.

The $K$ value of the negative binomial distribution was estimated to measures the degree of aggregation [25] using the following formula:

$$
K=m^{2} /\left(s^{2}-m\right)
$$

The value of $K>0, K<0$ and $K>8$ indicates aggregated, uniform and random distribution respectively.

\subsection{Evaluation of the Empirical Model Describing $P_{T}$ and $m$ Relationships}

The proportion relationships of infested fruits and the mean numbers of infested fruits per spikelet ( $P_{T}$ and $m$ respectively) were evaluated for LDM by using the following empirical model-equation of No. $4[30,35,53,54]$.

$$
\ln (m)=a+b \ln \left(-\ln \left[1-P_{T}\right]\right)
$$

where $T$ is a tally threshold which represents the numbers of infested fruits on a date palm spikelet required for the classification as infested $>T ; P_{T}$ is a proportion of infested fruits with $\leq T$ infested fruits; Tally thresholds of $0,1,2,3,4$ and 5 were used; parameters a and b of relationships of $\ln (m)$ on $\ln \left(1-P_{T}\right)$ estimated by regression. 


\subsection{Development of Binomial Sequential Sampling Plans for LDM}

Binomial sequential sampling plans based on the "presence/absence" of infested fruits on a spikelet were developed for LDM, depend on the above empirical model. Stop lines for each action threshold were developed based on the sequential probability ratio test SPRT by using the following equation [55]. Tally threshold ( $T=3$ ) was selected for further development due to the relatively high coefficient of correlation values $\left(r^{2}\right)$ of the regression model (equation 5) [30,35,56].

$$
\begin{gathered}
T_{U}(n)=B n+A, \\
T_{L}(n)=B n-C \\
B=\ln \left[\left(1-P_{0}\right) /\left(1-P_{1}\right)\right] / \ln \left[P_{1}\left(1-P_{0}\right) /\left(P_{0}\left(1-P_{1}\right)\right)\right] \\
A=\ln [(1-\beta) / \alpha] / \ln \left[P_{1}\left(1-P_{0}\right) /\left(P_{0}\left(1-P_{1}\right)\right)\right] \\
C=\ln [\beta /(1-\alpha)] / \ln \left[P_{1}\left(1-P_{0}\right) /\left(P_{0}\left(1-P_{1}\right)\right)\right]
\end{gathered}
$$

where $\mathrm{n}=$ the total number of samples; $T_{(n)}=$ the cumulated numbers of spikelets with at least $\mathrm{T}$ infested fruit (sampling unit). The upper $\left(P_{1}\right)$ and lower $\left(P_{0}\right)$ boundaries were set a maximum of \pm 0.15 of action threshold proportions $(0.15,0.25$, and 0.35$) ; B=$ slope, $A$ and $C=$ the upper intercept and lower intercept; Lower line $(L)$ and upper lines $(U)$ with type $I$ and $I I$ error which set at $\alpha$ and $\beta=0.10$ or 0.05 . Type $I$ error is defined as treatment when the LDM infestation is less than the economic threshold and type $I I$ error is defined if the sampled date palm plantation is not treated when the LDM intensity is higher than ET.

Binomial sampling plans were validated using the Resampling for Validation of Sample Plans (RVSP) software [57] at only $T=3$. Program requirements are preset parameters $\alpha$ and $\beta=0.05$ and 0.10 ; the boundaries of P1 and P0 were set to have a maximum of \pm 0.15 of $P_{A T}$, with a minimum sample size $=10$. RVSP performed 500 resampling iterations with replacement were simulated for each data set of the twenty-eight independent plantations. Operating characteristics (OC) and average sample size (ASN) for function each proportion of action threshold (AT) were performed in RVSP to validate the binomial models of sequential sampling plans for LDM; the OC and ASN values were plotted against the proportion of infested plants with $\mathrm{T}$ number of infested fruits. The regression models were analyzed and the plots of OC and ASN were generated by using SigmaPlot 14.5 software, whereas the binomial sampling models were plotted by using Microsoft Office Excel (2016).

\section{Results}

\subsection{Spatial Distribution}

The infestation rate of LDM ranged from a mean of 0.521 to 11.875 infested fruits /spikelets in the dataset for developing binomial sampling plans, and from 0.375 to 9.500 infested fruits/spikelets in the validation dataset. TPL regression model revealed that a strong relationship between variance and mean of LDM. Taylor's b value which was significantly greater than $1.00\left(b=1.4041, a=0.0695, r^{2}=.781, t=4.927, P<0.0001\right.$; Fig 1$)$ indicated an aggregated dispersion. Furthermore, the clumped parameter $(K$ value $=2.565)$ showed aggregation distribution of LDM infesting date palm fruits.

\subsection{Binomial Sampling plans}

\subsubsection{Tally Threshold Determination}

The significant relationship between the mean number of infested fruits and proportion infested spikelets $\left(P_{T-m}\right)$ models revealed relatively robust fits for LDM infesting date palm fruits (Table 1). As the mean number of infested fruit increased, the proportion of infested spikelets increased as well. The model with $T=3$ and 4 showed relatively strong fit $\left(r^{2}=0.856\right.$ and 0.866 respectively, $\left.P<0.0001\right)$ and were the most predictive for the sampling plan. However, $T=3$ (Fig 2) was chosen for binomial sampling plan development because both tally thresholds ( $T=3$ and 4 ) had almost the same relatively high coefficient 
of correlation values $\left(r^{2}\right)$ of the regression models. However, the Models describing PT-m relationships with $T=0,1$, and 2 were relatively weak $\left(r^{2}<0.73\right)$ and may not be appropriate to further develop binomial sampling plans for LDM.

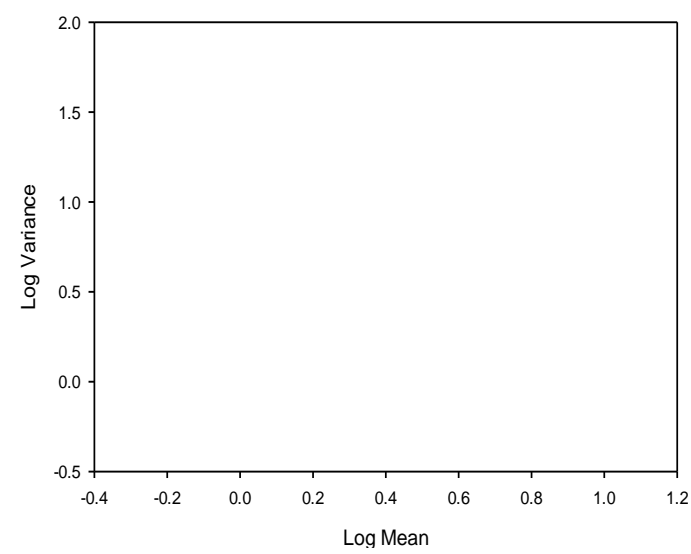

Figure 1. Taylor Power Law regression for Lesser Date Moth in date palm.

Table 1. Estimated parameters from mean vs. proportion regression models with different tally thresholds for date palm fruits infesting by Lesser Date Moth in date palm plantations in Basra during 2017-2019 growing seasons. .

\begin{tabular}{cccccc}
\hline \multirow{2}{*}{$T$} & \multirow{2}{*}{$\mathrm{N}$} & Intercept & Slope & \multirow{2}{*}{ MSE } & \multirow{2}{*}{$r^{2}$} \\
\cline { 3 - 4 } & & $a \pm \mathrm{SE}$ & $b \pm \mathrm{SE}$ & & 0.0629 \\
0 & 52 & $-0.138 \pm 0.054$ & $0.551 \pm 0.060$ & 0.084 & 0.629 \\
1 & 53 & $-0.420 \pm 0.067$ & $0.674 \pm 0.074$ & 0.129 & 0.621 \\
2 & 55 & $-0.927 \pm 0.059$ & $0.735 \pm 0.061$ & 0.099 & 0.729 \\
3 & 50 & $-2.878 \pm 0.112$ & $1.960 \pm 0.101$ & 0.239 & 0.856 \\
4 & 43 & $-3.796 \pm 0.132$ & $2.008 \pm 0.125$ & 0.237 & 0.866 \\
5 & 26 & $-4.052 \pm 0.240$ & $1.979 \pm 0.179$ & 0.298 & 0.842 \\
\hline
\end{tabular}

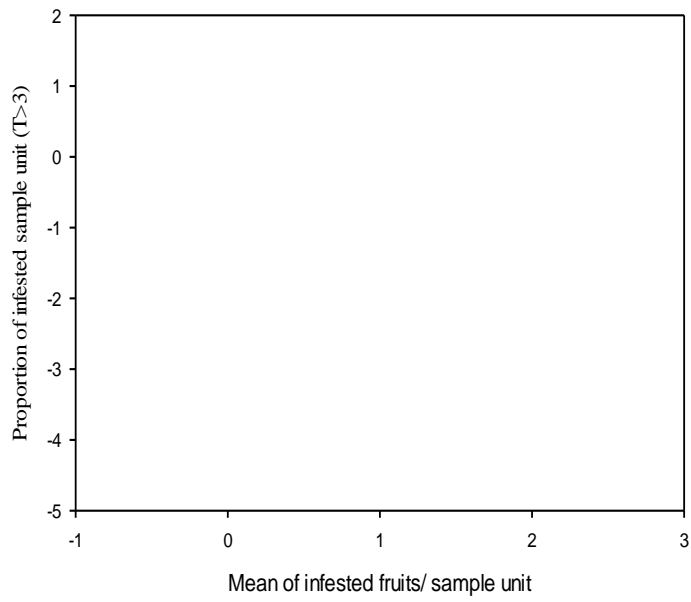

Figure 2. Empirical relationship curve between the proportion of spikelets infested with 3 or more infested fruits and the average number of infested fruits per spikelets. 


\subsubsection{Development of Wald's SPRT binomial sequential sampling plans}

Binomial sampling plans were developed with tally threshold $T=3$ at three action threshold proportions $(0.15,0.25$, and 0.35$)$ corresponding to the mean of numbers of infested fruits of less than 10 infested fruits per spikelet ( $=0.35)$ (Fig. 3). They are utilized to an injury classification of LDM infestation as above or below economic thresholds depending on presence/absence total numbers on defined sample units. Indeed, if the cumulative number of infested spikelets (sample units) increases above the upper stop line, then management procedure is recommended because LDM infestation is probably to be above the action threshold. Otherwise, if the cumulative number of infested spikelets falls below the lower stop line; at that point, the management procedure is not recommended because the infestation is likely to be below the action threshold. Total numbers that fall between stop lines after a maximum number of samples have been taken would also lead to no management recommendation, however, a resampling would likely be needed following a characterized number of days. However, our proposal to terminate sampling at 90 samples and resampling after the following 7 days if necessary as these are acceptable for pest control professionals in managing sampling LDM in date palm plantations.

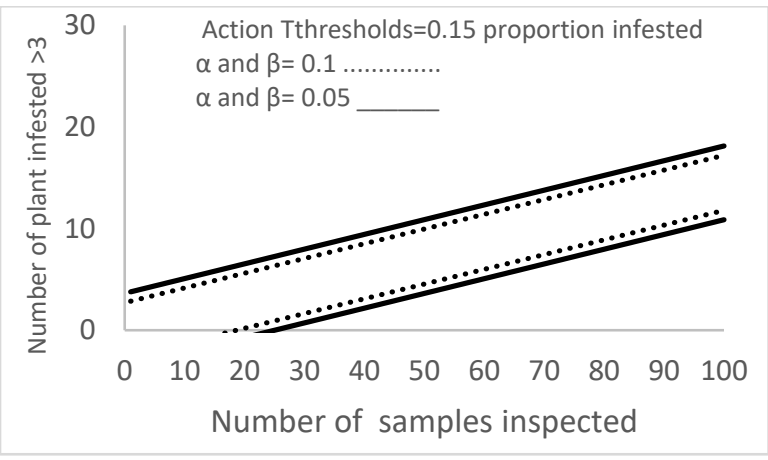

(a)

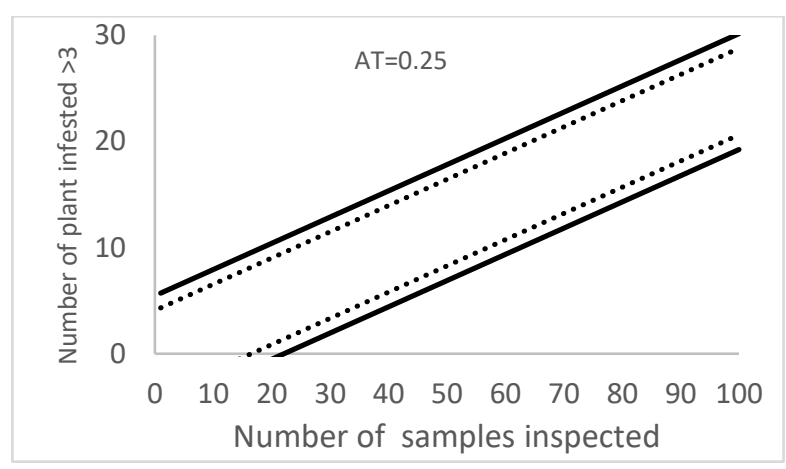

(b)

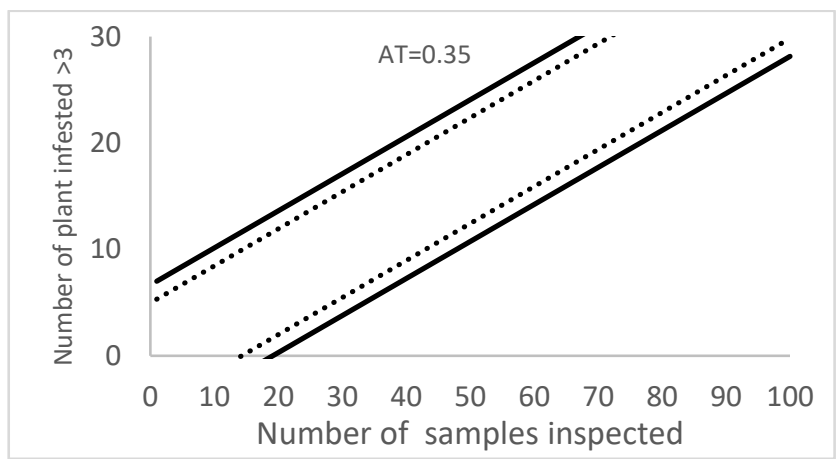

(c)

Figure 3. Decision stop lines for binomial sequential sampling plans for LDM-infested date palm fruit proportion action thresholds of (A) 0.15 (B) 0.25 and (C) 0.35 on spikelet (sampling unit) during the growing season in Basra. Tally thresholds were set at zero (T>3). Error parameters $\alpha$ and $\beta$ were set at 0.05 (dashed line) and 0.1 (solid line).

\subsubsection{Validation of Sampling Protocols}

Binomial sequential sampling plans for LDM were validated by evaluating the OC and ASN functions of the action thresholds $(0.15,0.25$, and 0.35$)$ at a tally threshold of $T=3$ that are illustrated in Fig. 4 [57]. The OC values, which define the precision of the sampling plans, represent the probability of no action when the pest populations reach a specified density. While ASNs indicate the efficacy of the sampling plans and refer to the required sample size to make the proper pest management decision. The proportion of spikelets infested By LDM in validation fields ranged from 0.041 to 1.00 , and the OC functions were influenced slightly by changes to the ATs and decreasing the probability of error $\alpha$ and $\beta$ 
from 0.1 to 0.05 (Fig. 4, Table 3). However, and as expected, changes to the $A T^{\prime}$ s and $\alpha$ and $\beta$ error rates altered ASN significantly. For example, an ASN of 38 was required and decreased to $28 \alpha$ and $\beta$ set at 0.05 at the action threshold of 0.15 of infested spikelets. By increasing the AT to 0.25 , the ASN increased to 46 and 32 at $\alpha$ and $\beta$ to 0.05 and 0.1 , respectively. In general, the steep slope around the ideal operating characteristics value of 0.5 are reflective of the accurate and precise sampling plans [24,58,59]. Among validated $A T \mathrm{~s}$, the sampling plan appears to operate optimally at 0.25 and 0.35 proportion (25 and $35 \%$ spikelets infested with $T>3$ ) have closest value of the operating characteristic of 0.5 and reflect the most preferred and accurate plans. Depending on the relevant ASN curves, sample sizes are required to reach the base of the sampling stop lines were about 46 and 32 for $A T$ of 0.25 and about 43 and 31 for $A T$ of 0.35 at $\alpha$ and $\beta$ to 0.05 and 0.1 , respectively.

Table 3. Summary of the validation of SPRT binomial sequential sampling plans by using RVSP for infested date palm fruits by LDM.

\begin{tabular}{ccccc}
\hline & \multicolumn{3}{c}{ Average of statistics for 500 sequential sampling iterations } \\
\cline { 2 - 5 } AT & \multicolumn{3}{c}{ OC } & \multicolumn{3}{c}{ ASN } \\
\cline { 2 - 5 } & 0.05 & 0.1 & 0.05 & 0.1 \\
\hline 0.15 & 0.248 & 0.245 & 38 & 28 \\
0.25 & 0.443 & 0.436 & 46 & 32 \\
0.35 & 0.509 & 0.512 & 43 & 31 \\
\hline
\end{tabular}
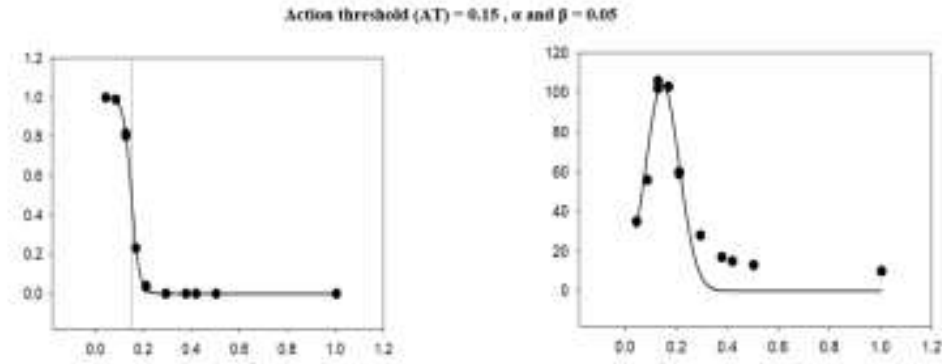

(a)

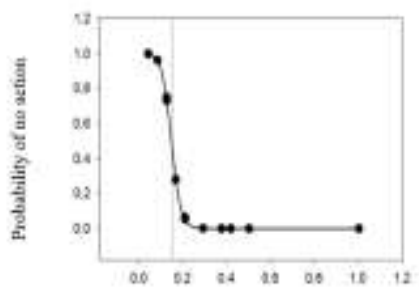

(b)

(c)

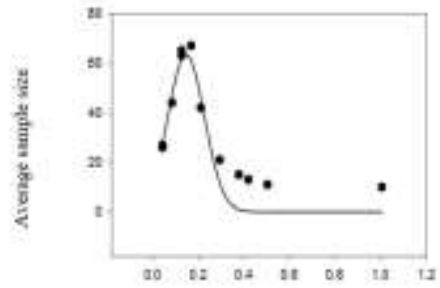

(d)

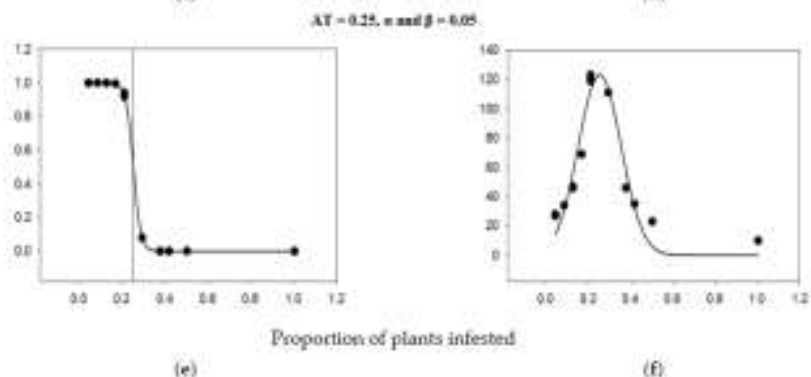

Figure 4. Operating characteristic (OC) (a, c, e, g, i, and k) average sample number (ASN) (b, d, f, h, j, and l) for binomial Scheme 0.0 .25 and 0.35 and 0.50 proportion of spikelets infested with at least three infested fruits (T>3) with error parameters $\alpha$ and $\beta$ $=0.05$ and 0.1 . 


\section{Discussion}

There are no accurate economic thresholds for LDM infesting date palm plantations in the Province of Basra. Furthermore, the producers are disinclined to risk and are routinely noticed using insecticides at much lower LDM infestation levels [10]. Thus, establishing an initial monitoring procedures is expected to determine LDM population densities and develop a more preferred and reliable sampling plan in IPM program, which is fundamental for making a control decision of the pest [15]. For that, checking infested or uninfested spikelets, instead of sampling all infested fruits per spikelet per a palm, might be utilized as an efficient sampling technique. Considering these perceptions, Binomial sampling plans were developed for LDM infesting date palms. Knowledge about the spatial distribution or the degree of aggregation for an insect species greatly affects sample size requirements for sampling plans used to estimate or classify pest densities [18,19]. The spatial distribution indices indicated that the LDM has an aggregated/ clumped distribution in date palm plantations; similar results were obtained to carob moth (Lepidoptera: Pyralidae) infested the fruits of date palms in California Date Gardens; Park and Perring [21] reported $b$ coefficient from TPL regressions of $>1$.

In our study, Binomial sampling plans were developed with tally threshold $T=3$ at four action threshold proportions $(0.15,0.25$, and 0.35$)$. Sample sizes always increase when intensities are close to the action threshold, but for low and high intensities, the ASNs are not prohibitive for making management decisions. Choosing lower $\alpha$ and $\beta$ rates decrease the expected errors of the sampling plans, but this must be weighed against the cost of increasing sample size required to make treatment decisions. Overall, ASN numbers (Table 3) seem reasonable relative to those for LDM in date palms, and deployment of the binomial sequential sampling for LDM in date palm would likely be acceptable, especially with error rates for $\alpha$ and $\beta$ set at 0.1 . Binomial sequential sampling plans were developed and validated for LDM in Basra, and these plans when utilized for IPM decision making should save time and costs over enumerative sequential sampling plans $[29,45,60]$.

The sampling procedure arising out of this work is reliable and correspond to existed sampling programs of date palm insects [21-23]. The slopes and width of indecision zones for these binomial sequential sampling plans (Figs. 3) were developed using standard formulas that reflect economic threshold values, the degree of population clumping, and acceptable Type I and II error rates [57]. They function to classify LDM intensities as above or below economic thresholds based on presence-absence counts on specified sample units. We recommend terminating sampling at 90 samples and resampling after 7 days if needed as these are acceptable for pest management specialists sampling LDM in date palm plantations.

Author Contributions: Conceptualization, A.A. and M.M.A.; methodology, A.A. and M.M.A.; software, A.A.; validation, A.A., M.M.A and R.A.M..; formal analysis, A.A.; investigation A.A., M.M.A and R.A.M; resources, A.A.; data curation, A.A.; writing-original draft preparation, A.A.; writing-review and editing, A.A.; visualization, A.A.; supervision, A.A., and M.M.A; project administration, A.A. and M.M.A. All authors have read and agreed to the published version of the manuscript.

Funding: This research received no external funding.

Institutional Review Board Statement: Not applicable.

Informed Consent Statement: Not applicable.

Data Availability Statement: The data that support the findings of this study are available from the corresponding author, Aqeel Alyousuf, upon reasonable request.

Acknowledgments: The authors thank the staff of Department of Plant Protection staff, Ministry of Agriculture, Iraq, for technical support.

Conflicts of Interest: The authors declare no conflict of interest. 


\section{References}

1. Johnson, D. Worldwide dispersal of the date palm from its homeland. In Proceedings of IV International Date Palm Conference 2010, pp. 369-375.

2. Statista. Dried fruit production worldwide by type 2019/2020, https://www.statista.com/statistics/959950/dried-fruits-globalproduction-by-type/. 2021.

3. CSO ( Central Statistical Organization). Comparison between dates production and average yield per productive palm in production stage in Iraq (2016-2020). from Central Statistical Organization, Iraq http://cosit.gov.iq/ar/agri-stat/agri-other-2. 2021.

4. Latifian, M.; Soleyman, N.E. Study of the Lesser moth Batrachedra amydraula (Lep.: Batrachedridae) distribution based on geostatistical models in Khuzestan province. Journal of Entomological Research 2009, 1, 43-55.

5. El-Shafei, W. Population Density of some Insect Pests Infesting Fallen Soft Dates and their Associated Natural Enemies in Giza Governorate, Egypt. Journal of Plant Protection and Pathology 2018, 9, 815-821.

6. Shayesteh, N.; Marouf, A.; Amir-Maafi, M. Some biological characteristics of the Batrachedra amydraula Meyrick (Lepidoptera: Batrachedridae) on main varieties of dry and semi-dry date palm of Iran. 10th International Working Conference on Stored Product Protection. Julius-Kühn-Archiv 2010, 151-155.

7. Kakar, M.; Nizamani, S.; Rustamani, M.; Khuhro, R. Periodical lesser date moth infestation on intact and dropped fruits. Sarhad Journal of Agriculture 2010, 26, 393-396.

8. Perring, T.M.; El-Shafie, H.A.; Wakil, W. Carob moth, lesser date moth, and raisin moth. In Sustainable pest management in date palm: Current status and emerging challenges, Springer: 2015, 109-167.

9. Alyousuf, A.; Mezeal, M. Study of the Lesser Date Moth infestation and economic losses on Date Palm cvs. Sayer and Halawy. Basrah journal for date palm research 2008, 7, 1-11.

10. Al-Jboory, I.; Hamudi, R.; Al-Jamali, N.; Zwain, K.; Taha, H. The direct and indirect effect of dubas and lesser date moth control on date palm and citrus pests. Iraqi J. Agric 1999, 4, 61-67.

11. Al-Jorany, R.S.; Al-Jboory, I.J.; Hassan, N. Evaluation of the sex pheromone efficiency of the Lesser Date Moth, Batrachedra amydraula Meyrick (Lepidoptera: Batrachedridae). Baghdad, Iraq. J. Life Sciences 2015, 9, 242-247.

12. Ali, A.-S.A.; Hama, N.N. Integrated management for major date palm pests in Iraq. Emirates Journal of Food and Agriculture 2016, 24-33.

13. Bajwa, W.I.; Kogan, M. Compendium of IPM Definitions (CID)-What is IPM and how is it defined in the Worldwide Literature. IPPC publication 2002, 998, 1-14.

14. Pedigo, L.P.; Buntin, G.D. Handbook of sampling methods for arthropods in agriculture; CRC Press: 1994.

15. Binns, M.; Nyrop, J. Sampling insect populations for the purpose of IPM decision making. Annual Review of Entomology 1992, 37, 427-453.

16. Hassell, M.P.; May, R.M. Stability in insect host-parasite models. The Journal of Animal Ecology 1973, 693-726.

17. Winder, L.; Griffiths, G.; Perry, J.; Alexander, C.; Holland, J.; Kennedy, P.; Birt, A. The role of large-scale spatially explicit and small-scale localized processes on the population dynamics of cereal aphids. Bulletin of entomological research 2005, 95, 579-587.

18. Davis, P.M. Statistics for describing populations. Handbook of sampling methods for arthropods in agriculture 1994, 33-54.

19. Pedigo, L.P. introduction to sampling arthropod population. Handbook of sampling methods for arthropods in agriculture, LP Pedigo and GD Buntin (eds):1-11.; CRC Press: 1994a.

20. Nay, J.E.; Park, Y.-L.; Perring, T.M. Effect of bunch sanitation on spatial distributions of abscised fruit and phycitine moths (Lepidoptera: Pyralidae) in California date gardens. Journal of economic entomology 2007, 100, 1773-1780.

21. Park, J.-J.; Perring, T.M. Development of a binomial sampling plan for the carob moth (Lepidoptera: Pyralidae), a pest of California dates. Journal of economic entomology 2010, 103, 1474-1482.

22. Arbab, A.; Bakry, M. Spatial Distribution and Minimum Sample Size for Monitoring of Parlatoria Date Scale Insect, Parlatoria blanchardi (Targioni-Tozzetti) (Hemiptera: Diaspididae) on Date Palm Trees. Agricultural Research E Technology: Open Access Journal 2016, 2, 79-90.

23. Faleiro, J.; Abdallah, A.B.; Kumar, J.A.; Shagagh, A.; Al Abdan, S. Sequential sampling plan for area-wide management of Rhynchophorus ferrugineus (Olivier) in date palm plantations of Saudi Arabia. International Journal of Tropical Insect Science 2010, 30, 145-153.

24. Binns, M. Sequential sampling for classifying pest status. Handbook of sampling methods for arthropods in agriculture. CRC, Boca Raton, FL 1994, 137-174.

25. Southwood, T. The sampling programme and measurement and description of dispersion. In: Ecological methods: with particular reference to the study of insect's populations; 2nd, Ed. Chapman and Hall: 1978.

26. Buntin, G.D. Developing a primary sampling program. Handbook of sampling methods for arthropods in agriculture, LP Pedigo and GD Buntin (eds) 1994, 99-115.

27. Pedigo, L.; Rice, M. Economic decision levels for pest populations. Entomology and pest management 2006, $253-284$.

28. Soto-Rojas, L.; Rodríguez-Leyva, E.; Bautista-Martínez, N.; Ruíz-Galván, I.; García-Palacios, D. Sequential and Binomial Sampling Plans to Estimate Thrips tabaci Population Density on Onion. Insects 2021, 12, 331.

29. Ferrer, M.C. Financial impact analysis of IPM with conventional sampling and IPM with binomial sequential sampling method to traditionally operated farms for collards, 2007. Clemson University, 2008. 
30. Giles, K.L.; Royer, T.A.; Elliott, N.C.; Kindler, S. Development and validation of a binomial sequential sampling plan for the greenbug (Homoptera: Aphididae) infesting winter wheat in the southern plains. Journal of economic entomology 2000a, 93, 15221530.

31. Elliott, N.; Giles, K.; Royer, T.; Kindler, S.; Tao, F.; Jones, D.; Cuperus, G. Fixed precision sequential sampling plans for the greenbug and bird cherry-oat aphid (Homoptera: Aphididae) in winter wheat. Journal of economic entomology 2003, 96, 15851593.

32. Boeve, P.J.; Weiss, M.J. Binomial sequential sampling plans for cereal aphids (Homoptera: Aphididae) in spring wheat. Journal of economic entomology 1997, 90, 967-975.

33. Severtson, D.; Flower, K.; Nansen, C. Spatially-optimized sequential sampling plan for cabbage aphids Brevicoryne brassicae L.(Hemiptera: Aphididae) in canola fields. Journal of economic entomology 2016, 109, 1929-1935.

34. Fernandes, M.; Spessoto, R.; Degrande, P.; Rodrigues, T. Sequential sampling of Aphis gossypii Glover (Hemiptera: Aphididae) and Frankliniella schultzei Trybom (Thysanoptera: Thripidae) on cotton crop. Neotropical entomology 2011, 40, $258-263$.

35. Alyousuf, A. Sampling plans for aphids on winter canola. Dissertation, OSU, USA, 2018.

36. Elliott, N.; Brewer, M.; Giles, K.; Backoulou, G.; McCornack, B.P.; Pendleton, B.; Royer, T. Sequential sampling for panicle caterpillars (Lepidoptera: Noctuidae) in sorghum. Journal of economic entomology 2014, 107, 846-853.

37. da Silva Stefanelo, L.; Cargnelutti Filho, A.; Guedes, J.V.C.; us; Sturmer, G.R.; Facco, G.; de Bem, C.M. Sequential sampling for evaluation of caterpillars, small and large in soybean. African Journal of Agricultural Research 2017, 12, 932-943.

38. Kim, K.; Toepfer, S. Evaluation of a first-event sampling model for monitoring cabbage pests. Journal of Entomological and Acarological Research 2021, 53.

39. Hong, B.; Nowatzki, T.M.; Sult, T.S.; Owens, E.D.; Pilcher, C.D. Sequential sampling plan for assessing corn rootworm (Coleoptera: Chrysomelidae) larval injury to Bt maize. Crop Protection 2016, 82, 36-44.

40. Hamilton, G.C.; Lashomb, J.H.; Arpaia, S.; Chianese, R.; Mayer, M. Sequential sampling plans for Colorado potato beetle (Coleoptera: Chrysomelidae) in eggplant. Environmental entomology 1998, 27, 33-38.

41. Grigolli, J.; Souza, L.; Mota, T.; Fernandes, M.; Busoli, A. Sequential sampling plan of Anthonomus grandis (Coleoptera: Curculionidae) in cotton plants. Journal of economic entomology 2017, 110, 763-769.

42. Nicácio, J.; Oliveira, I.D.; Uchoa, M.A.; Faccenda, O.; Abot, A.R.; Fernandes, M.G.; Garcia, F.R. Sequential sampling plan for fruit fly species of the Genus Anastrepha (Diptera: Tephritidae) in guava orchards. Anais da Academia Brasileira de Ciências 2018, 90, 3607-3614.

43. Arbab, A.; Mirphakhar, F. Spatial distribution pattern and sequential sampling plans for Bactrocera oleae (Gmelin)(Dip: Tephritidae) in olive orchards. Journal of Entomological and Acarological Research 2016, 48, 23-28.

44. Pulakkatu-Thodi, I.; Gutierrez-Coarite, R.; Wright, M.G. Dispersion and optimization of sequential sampling plans for coffee berry borer (Coleoptera: Curculionidae) infestations in Hawaii. Environmental entomology 2018, 47, 1306-1313.

45. Naranjo, S.E.; Flint, H.M.; Henneberry, T.J. Binomial sampling plans for estimating and classifying population density of adult Bemisia tabaci in cotton. Entomologia experimentalis et applicata 1996, 80, 343-353.

46. Binns, M.R.; Nyrop, J.P.; van der Werf, W.; Werf, W. Sampling and monitoring in crop protection: the theoretical basis for developing practical decision guides; CABI: 2000.

47. Ahuja, D.; Ahuja, U.R.; Singh, S.; Singh, N. Comparison of Integrated Pest Management approaches and conventional (nonIPM) practices in late-winter-season cauliflower in Northern India. Crop Protection 2015, 78, 232-238.

48. Elliott, N.; Kieckhefer, R.; Walgenbachi, D. Binomial sequential sampling methods for cereal aphids in small grains. Journal of Economic Entomology 1990, 83, 1381-1387.

49. Giles, K.L.; Royer, T.A.; Elliott, N.; Kindler, S. Binomial sequential sampling of Rhopalosiphum padi in winter wheat in the Southern Plains. Southwestern Entomologist 2000b, 25, 191-199.

50. Hodgson, E.; Burkness, E.; Hutchison, W.; Ragsdale, D. Enumerative and binomial sequential sampling plans for soybean aphid (Homoptera: Aphididae) in soybean. Journal of economic entomology 2004, 97, 2127-2136.

51. McGraw, B.A.; Koppenhöfer, A.M. Development of binomial sequential sampling plans for forecasting Listronotus maculicollis (Coleoptera: Curculionidae) larvae based on the relationship to adult counts and turfgrass damage. Journal of economic entomology 2009, 102, 1325-1335.

52. Taylor, L. Aggregation, variance and the mean. Nature 1961, 189, 732-735.

53. Kono, T.; Sugino, T. On the estimation of the density of rice stems infested by the rice stem borer. Jpn. J. Appl. Entomol. Zool 1958, 2, 184-188.

54. Jones, V. Sequential estimation and classification procedures for binomial counts. In Pedigo, L. and Buntin, D. (eds) Handbook of sampling methods for arthropods in agriculture. CRC 1994, 175-205.

55. Wald, A. Sequential analysis. New York: J. Wiley E Sons 1947.

56. Royer, T.; Giles, K.; Elliott, N. Glance'n go sampling for greenbugs in winter wheat. Oklahoma Cooperative Extension Service, Oklahoma State University Extension Facts, L-307, Stillwater, OK 2002.

57. Naranjo, S.E.; Hutchison, W.D. Validation of arthropod sampling plans using a resampling approach: software and analysis. American Entomologist 1997, 43, 48-57.

58. Butler, C.D.; Trumble, J.T. Spatial dispersion and binomial sequential sampling for the potato psyllid (Hemiptera: Triozidae) on potato. Pest management science 2012, 68, 865-869. 
59. Gutierrez-Coarite, R.; Pulakkatu-Thodi, I.; Wright, M.G. Binomial Sequential Sampling Plans for Macadamia Felted Coccid (Hemiptera: Eriococcidae) Infesting Hawaii Macadamia Orchards. Environmental entomology 2019, 48, 219-226.

60. Naranjo, S.E.; Diehl, J.W.; Ellsworth, P.C. Sampling whiteflies in cotton: validation and analysis of enumerative and binomial plans. Environmental entomology 1997, 26, 777-788. 